\title{
THE EMERGING HUMAN-DATA INTERACTION IN UX RESEARCH FIELD
}

\author{
Fatemeh RAZMI \\ OsloMet - Oslo Metropolitan University
}

\begin{abstract}
In this era the extensiveness of data collection methods in user experience design is indeed undeniable due to the swiftly evolving contexts associated with users' personal data such as social media platforms and search engines. This creates a new discipline in UX research field which gives opportunities for designers to do UX research in innovative ways based on data concepts; one of these main concepts is called big data, the data that is collected from users by all types of companies and as its name suggests, it is some kind of data that cannot be easily processed because of its wideness. However, when this huge portion of information is somehow refined, it is time for designers to play their leading role to offer user-centred solutions based on the reports they got from big data. In the field of UX; one of the main responsibilities of a designer is to predict the future of products and services and also to help users have access to their desired goods or services even before they think that they might need them. Hence this paper will disclose how big data can benefit UX design research methods to change the nature of data information, to human data interactions that can support the proposed UX solution.
\end{abstract}

Keywords: Big data, UX research methods, interaction design, e-experience, technology

\section{INTRODUCTION: WAY OF THE FUTURE}

For millennia, mankind has looked to the divine for guidance and wisdom. We have always had this fascination with predicting and knowing what is to come [1]. Today designers have the same neverending obsession about knowing the future as our ancestors, this time not necessarily about our personal lives, but about user's future behaviour through methods such as experience mapping, service blueprinting or data science which is known as big data. The research question of this paper is focused on big data and it was explored through a former design project in collaboration with pharmacy association of Norway (Apotekforeningen) to practice the idea. If big data can benefit UX design research methods and if it eventually can change the modality of data information to human data interaction.

\subsection{UX is the key to unlocking big data}

There is a usual obstacle that possibly every designer has faced when designing the UX; we have a hard time proving that a particular feature would work better than others and that users would like it more. This problem occurs when we designers have nothing but our own competence and of course variety of inconclusive tests, interviews and surveys to approve our allegations. As I explained earlier in another paper [2], when it comes to design methods, traditional tools like interviewing or observation help designers to touch the surface of the users' lives, however a deeper understanding of users' feelings and thoughts will be obtained through generative methods like user experience research. Agreeing that old research methods are limited [2], the best alternative lies in data. UX design is the process of creating products that provide meaningful and relevant experiences to users; this involves the design of the entire process of acquiring and integrating the product, including aspects of branding, design, usability, and function [3], so far this contribution has been mostly down to testing the assumptions, but big data in UX can change it all. The biggest advantage in using big data is that the data is comprehensive, diverse and more importantly, generated by the users themselves. Nowadays you can easily obtain data on a wide variety of aspects; Screen interaction vantage points, average time spent on a single feature, features that get clicks are just a few of them [4]. Involving big data in UX research is empowering designers to see patterns and algorithms in huge amounts of data, since one of the crucial parts of UX 
design job is predicting and helping the users to have access to desired goods or services when or even before they think they need them. Taking advantage of big data in the era when we have much more data than ever is a good idea; especially when we want to design e-experience for users (when the target group is a crowd of thousands!) who dealing with each of them is a big challenge and also when it is difficult to validate between users' words and user's actions, we have to set aside traditional user research methods such as interviews and look for other options in our toolbox. We need to have a rigid empirical data that supports our proposed UX solution. Big data can be used when the presence of users in design process is insignificant in comparison with the total number of end users. UX designers have the opportunity to look beyond the so-called big data in an excel sheet, we have the ability to involve human intuition powered by elements such as psychology, ethnography studies and user research which brings empathy and behaviour to the table and is able to explain the big data with a lot more context around.

\section{METHODS: CASE STUDY OF A UX PROJECT IN PEDIATRIC HEALTHCARE IN NORWAY}

Several different research methods were chosen for this project based on Tuuli Mattelmäki's book [5] in which she explains that according to aim of the research, methods can be categorised into traditional and innovative methods. Traditional methods like interviews and observations are an ongoing component of any research, they typically produce knowledge of large masses of people, and results in figures, statistics and tables. Since the first step in every user-centred design process is to get to know the user, ethnographic research is chosen to delve into who the users are and the environment they engage with by contextual interviews. Subsequently, storytelling and mapping were used as innovative methods to cope with the complexity of this vast subject as these methods are creative and participatory and can lead us to concealed lives of our users with all their desire, needs, feelings, likes and dislikes. The key assumption that if using big data can benefit UX was practiced along a university project done at Oslo Metropolitan University in Norway, as some points of the project were linked to an ongoing similar project by the collaborative partner (Apotekforeningen) it was found that there are certain individuals who are particularly good sources of information. These people who are experts in medical and pharmaceutical industry, are especially knowledgeable about how relevant work is done and they have the role of key informants who are repeatedly called upon to provide important insights along the way.

\subsection{Case study: antibiotic adherence in children}

Regardless of how effective medications are, if patients do not follow the prescribed instructions, the whole healthcare system would be compromised. The case study is about a project focusing on children with intentional non-adherence, when they choose not to take their prescribed medication. The project was done in collaboration with pharmacy association of Norway (Apotekforeningen) in 2018 and it was part of an ongoing project to use technology as an intervention in medication adherence for patients with chronic illnesses. The final product was a combination of a digital platform and a physical pill packaging. The digital app was a gameplay for children, where healthcare providers could have access to infographic data as health records banking.

\section{FINDINGS}

Many people under report embarrassing behaviours and thoughts on survey, they want to look good, even though most surveys are anonymous. This is called social desirability bias [6]. It is the tendency to respond to questions whether in interviews or surveys in a socially acceptable direction, this occurs mainly for items or questions that deal with personally or socially sensitive content like healthcare. The case study documented that parents were asked if usually their children complete prescribed antibiotic courses and more than 90 percent answered yes, but when the same question was asked from healthcare experts the answer was different. We have learnt that when the user's actions tell us one thing and their words tell us another, it is time to call upon a secondary, in depth research method and in this case the data obtained from healthcare authorities and their reports.

By studying numbers, graphs and charts, it came forth that unlike what parents said in the interviews, in fact the majority of them have a strong parental decision making on their children treatments and they sometimes intentionally choose not to continue antibiotics once their child feels better and before 
completing the whole course of treatment. Data also showed a pattern in which parents who have a refusal attitude towards antibiotics, have the same rejection when it comes to childhood vaccination. They delay vaccinations or decide not to vaccinate their children, so medication in children up to a certain age (1-5 years old) is noticeably dependent on their parents, the review of data showed parents are the main decision makers after collecting the medicine from pharmacies and in most cases they rely on their own belief and knowledge when it comes to antibiotics or vaccinations rather healthcare instructions coming from experts.

Mapping and user journeys showed that not only the today's children are considered as digital natives, but most of their parents (if at the oldest they are approximately 50) belong to this generation. The data from governmental reports [7] related to overall time spent on electronic devices shows that in big cities "screen times" are often the family times and without exceptions video games are involved, it seems that in smaller cities individuals focus on separate tasks when using their smart devices (Figure 1).

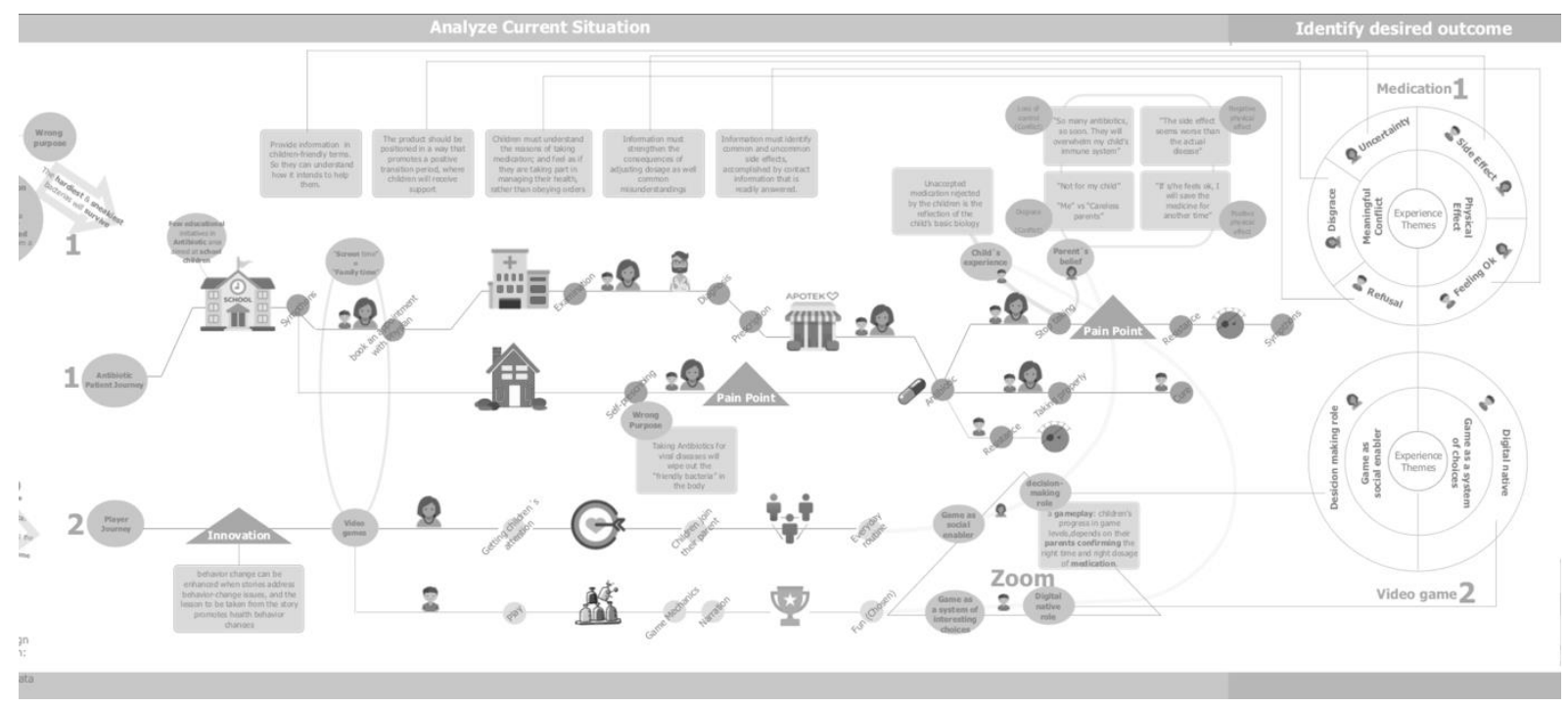

Figure 1. User journey and data mapping cleared out the pain points to improve

Storytelling sessions with children in a group and in a representative framework (a classroom) proved that it is helpful to put children in the story with familiar characters, since humans are inherently selfinterested [8]; the best way to make them care about the content of a narration is to make it about them. It was also advantageous to use narration when communicating with children due to the low intimacy with the target group, children under 7 years old.

Both users (children, parents, care givers) and stakeholders (E-health providers, Apotekforeningen) demand more from UX than just easier navigation and precision in screen taps. Integration of maps, a better in-app recommendation and a better and personalised search engine are a few of them that need to be optimised.

\section{DIscussion}

Like it or not, data is playing an increasingly important role in all of our lives and its role is going to get large. As explained by Angelina Obias [9], data driven design is all about optimisation and improving what you put out and it can be in one of the three main consumer facing areas (Figure 2). Case study project sought e-experience design with technology involved because the final digital product was supposed to be attached to an excising service. 


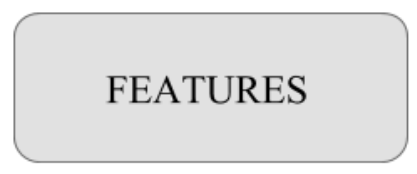

What will he do?

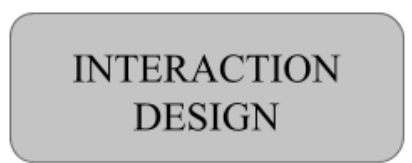

How will he do it?

What impression do

we want to give?

\section{CONTENT}

What will he need and want to know?

\section{Figure 2. The digital attributes that you could use data for}

There is a controversial discussion around big data and the role of intuition, many say intuition is useless when we have big amount of data to analyse. However, from designers' point of view even big data projects (in order to design a new product or service) are often driven by intuition. This is why everybody can act as a junior data scientist in design processes and explore the areas of improvements.

On the other hand, although the process related to data science is intuitive, intuition itself is not a science. moreover, whilst our gut feeling may usually give us a good general sense of how the world works, it is frequently not precise, we need data to sharpen the picture [4]. The data obtained from intuition will give us the preliminary material for analysing the "gut feeling" moments, and will help us analyse the algorithms, prediction and doing the things that if we wanted to do base on our own individual experience, we would not. We might have an intention about a special subject, but this intention can help us until a certain point, after that we have to rely on data which can correct the perspective of anybody even the best of us. What we qualify as data in this case study has some factors that in this context could context turn data-information to human-interaction:

Data has a new flow of the newest information. Frequently the value of data is not the size, it is that it can offer you new kinds of information to study - information that had never previously been collected [4]. For example, the relevance between non-adherence and vaccination rejection is one of the newest studies done in this field, or the quantitative data on total spent time on digital devices among families is changing constantly, and researchers need to be updated.

Another factor is that big data does not lie! There are many reasons that people lie a lot in both qualitative and quantitative user research methods, due to the social desirability bias people want to have their best impressions, both on others and on themselves, this makes the user research inaccurate especially if users' feelings, beliefs and behaviours are crucial in design process. Unlike the information gathered from traditional research methods, in big data there is a small chance that people enter distorted information when they are so sure that there is no judgement or observation for example the patient records from pharmacies that shows due to non-adherence to an antibiotic course there was usually requests for prescription refills.

Based on the case study, big data can help researchers to access the valuable, trustworthy information in an easy way, it is not just about the access, it is about recognising the right target group, studying them, finding out their honest opinion, offering a new habit and causing them to change their opinion if necessary, this could not be done in this project just by interviewing or based on surveys. There was a preliminary big data as the trigger.

The last reason that explains why big data is so powerful, is that although big data as its name suggests is so big, but it is possible to zoom in on a specific section of big data with the highest possible accuracy. So, because we have big data, we can understand the small data, its connections, its causes and its results in different locations and compare data by zooming in or out. Using big data, you can zoom in on geography, you can spot patterns among cities, town, neighbourhoods, large and small [4].

Both social media and search engines gather big data, it seems that the data collected from social media platforms is not as honest as the data gathered from search engines. People's searching for information is; in itself information. When and where they search for facts, quotes, jokes, places, persons, things or help, it turns out can tell us a lot more about what they really think, really desire, really fear and really do than anyone might have guessed. This is especially true since people sometimes don't so much query Google as confide in it [4]. 


\section{"The ability to truly understand someone other than you, is not something that can be broken down into ones and zeroes."}

\section{Christian Madsbjerg}

Big data is obviously hot in the market, few would argue that; yet the devotee of big data feel it is crucial to understand why a user does something and quite frankly the "why" is something that big data usually cannot tell us, it can tell us something is happening, but to understand the messy human experience behind that data point, we need UX [10] to change the nature of data-information to human datainteraction in order to give us a better understanding of our users and their concealed lives.

\section{REFERENCES}

[1] Swart T. (2015) From prophecy into history: Proof of Gods hand on the Bible. Franklin, TN: Carpenters Son Publishing.

[2] Razmi F. Social network, a potential tool for UX research. In International Conference on Engineering Design, London, UK, September 2018, pp.86-91 (The Design Society, Institution of Engineering Designers).

[3] IDF. What is User Experience (UX) Design? (n.d.). Retrieved from: https://www.interactiondesign.org/literature/topics/ux-design [Accessed on 2019, 10 February].

[4] Everly R. (n.d.). How Big Data Can Help Designers Create a Better UX » Paul Olyslager. Retrieved February 2019, from https://www.paulolyslager.com/big-data-designers-create-ux/.

[5] Mattelmäki T. (2008). Design probes. Helsinki: University of Art and Design Helsinki.

[6] Stephens-Davidowitz S. and Pinker S. (2018). Everybody lies: What the internet can tell us about who we really are. Sydney: Bloomsbury.

[7] Regjeringen.no. (n.d.). Retrieved February 2019, from https://www.regjeringen.no/no/id4/.

[8] Dagenhard C. (2018). How to Use Storytelling to Enhance Your Healthcare Content. [online] Kunocreative.com. Available at: https:// www.kunocreative.com/blog/enhance-healthcarecontent [Accessed 13 May 2018]).

[9] Obias A. (n.d.). What Data do you need for Data Driven Design? » Paul Olyslager. Retrieved February 2019, from https://www.paulolyslager.com/data-need-data-driven-design/.

[10] Why big data and UX need each other | UserZoom UX blog. (2018, November 27). Retrieved February 2019, from https://www.userzoom.com/blog/why-big-data-and-ux-need-each-other/. 